\title{
Gastric adenocarcinoma among Hmong in California, USA, 1988-2000
}

\author{
Richard C. Yang, Paul K. Mills, and Deborah G. Riordan \\ Public Health Institute, Cancer Registry of Central California, 1320 E. Shaw Ave., Suite 160, Fresno, CA 93710, USA
}

\begin{abstract}
Background. This study examined gastric adenocarcinoma incidence, mortality, and tumor characteristics in the Hmong population of California, 1988-2000. Many Hmong relocated to the United States at the conclusion of the Vietnam War. Resettlement difficulties encountered by Hmong have included socioeconomic and healthcare issues. Hmong are wary of Western medicine and would resort to it as the last option, which may delay the diagnosis and treatment of diseases such as cancer.

Methods. Data from the California Cancer Registry were used to calculate incidence and mortality rates for Hmong, and were compared to these in Asian Pacific Islanders (API) and non-Hispanic whites (NHW). The population at risk was estimated through linear interpolation, using data from the 1990 and 2000 decennial censuses.

Results. Hmong experienced incidence and mortality rates of gastric adenocarcinoma several times higher than those of API and NHW. More than 97\% of Hmong patients chose no treatment, compared to only $25.6 \%$ of API and $30.3 \%$ of NHW patients. Hmong were more likely to be diagnosed with cancer at later stages but at better histologic grades than API and NHW.

Conclusions. Further investigations into Helicobacter pylori, Epstein-Barr virus, acid reflux, and dietary practices of Hmong living in the United States are needed before any firm conclusion can be made, as these risk factors may impact gastric cancer development. Hmong should also be encouraged to use traditional and Western medicines simultaneously, provided that traditional healthcare practices do not interfere with biomedicines.
\end{abstract}

Key words Hmong $\cdot$ Cancer $\cdot$ Health $\cdot$ Stomach cancer

Offprint requests to: R.C. Yang

Received: August 6, 2004 / Accepted: January 5, 2005

\section{Introduction}

The Hmong are an ethnic minority who migrated from China into the northern regions of Vietnam, Laos, and Thailand in the mid-1800s. For many decades the Hmong led a secluded and peaceful existence, surviving on subsistence agricultural practices and foraging. During the Vietnam War many Hmong were recruited by the United States Central Intelligence Agency (CIA) to fight its popularly known "CIA Secret War" in Laos and rescue downed United States pilots in the main conflict in Vietnam [1]. The fall of Saigon in 1975 forced approximately $300000 \mathrm{Hmong}$ to flee into refugee camps in neighboring Thailand, from which most eventually resettled in the United States [2].

In the United States, Hmong resettlements have concentrated in Minnesota, Wisconsin, and California. Currently, about 70000 Hmong reside in California alone [3]. Hmong encounter numerous socioeconomic and healthcare challenges. Differences in health belief systems often cause conflicts between the health-legal system and many Hmong families [4]. Consequently, Hmong are wary of Western medicine [5], and would consider biomedicines only as a last resort, which may delay the early diagnosis and treatment of diseases such as cancer.

From 1900 to 1950, gastric carcinoma was the first and third leading cancer mortality for men and women in the United States [6], respectively. The disease was diagnosed in approximately 22000 to 24000 people each year. Risk factors associated with gastric carcinoma include genetic predisposition [7,8]; infection with Epstein-Barr virus $[9,10]$; intake of large amounts of rice; high levels of alcohol consumption; and the intake of preserved, smoked, cured, pickled, and fermented foods that are high in salt, nitrite, and preformed $\mathrm{N}$-nitroso compounds [11,12]. Consumption of moldy foods [13] and frequent intake of meat-based meals [14] also elevate stomach cancer risk. However, the most 
influential risk factor of gastric cancer is infection with Helicobacter pylori. The relationship between $H$. pylori and stomach cancer was established in the early 1990s by several studies [15-17], which led to H. pylori being classified as carcinogenic to humans [18].

Furthermore, risk of stomach cancer is associated with socioeconomic status. Gastric carcinoma affects mostly people with low socioeconomic status and low literacy levels, as lower social class is associated with poor living conditions [19-21]. The male-to-female ratios range from 1.5 to 2.5 [22]. Asians have higher incidence rates than other ethnic racial groups. Japan has the highest stomach cancer rates [23]. Moderately high gastric cancer rates are observed in Korea, China, the Middle East, parts of Eastern Europe, and Central and South America. North America, Australia, New Zealand, India, and Northern Europe have the lowest rates of gastric cancer [24].

Globally, stomach cancer incidence and mortality have declined steadily since the early 1970s [25]. The invention of refrigeration technologies decreased the intake of salted, smoked, pickled, and cured food items [26], which led to the declining trends of stomach cancer incidence and mortality. Other contributing factors have included improved living conditions and the development of antibacterial medications [27]. However, gastric cancer is still a major health issue in the Hmong, as there is no simple screening tool to detect it [28]. In this study, patterns of gastric carcinoma development (i.e., incidence rates, mortality rates, stage at diagnosis, and trends over time) among Hmong in California from 1988 through 2000 were evaluated, and compared to the incidence and mortality rates of nonHispanic Whites (NHW) and Asian Pacific Islanders (API).

\section{Patients, materials, and methods}

Gastric cancer data utilized in this study were obtained from the California Cancer Registry (CCR). The CCR is a state-mandated, population-based cancer registry charged with abstracting cancer data from computerized hospital cancer registries, private pathology laboratories, and other "case-finding" sources since 1988. The methods of the CCR have previously been described [29].

Patients selected for this analysis were Hmong, API, and NHW in California who were diagnosed with stomach cancer from 1988 through 2000. The API and NHW cases were included for comparison purposes. To ensure accurate incidence and mortality rates, the true number of Hmong stomach cancer cases was determined by a previously developed case identification and reclassification algorithm [30].
The Hmong population at risk of developing stomach cancer from 1988 through 2000 was estimated by linear interpolation on an age-, calendar year- and genderspecific basis, using data from the 1990 and 2000 decennial United States censuses. Incidence and mortality rates calculated in this study used the direct method [31] and were based on invasive, malignant gastric carcinoma cases. In-situ cases were included for descriptive analyses only. The total number of available Hmong cases was too small for year-specific analyses of rates. Thus, calendar time incidence and mortality trends of gastric carcinoma among Hmong were analyzed for three different time periods (1988 through 1991, 1992 through 1995, 1996 through 2000). Information on age, tumor stage and grade at diagnosis, histological subtype, and anatomic subsites was also examined.

\section{Results}

Seventy-six gastric cancer cases were diagnosed among the Hmong living in California from 1988 through 2000. More than $97 \%$ of these cases were malignant tumors. From 1988 through 1991, the annual average age-adjusted incidence rate for stomach cancer in the Hmong was 26.9/100000, compared to $19.8 / 100000$ for API and 8.4/100 000 for NHW (Fig. 1). While the incidence rate for Hmong increased to 28.8/100000 from 1992 through 1995, the incidence rates dropped to 19.1/100000 for API and 7.4/100000 for NHW. As the incidence rate for Hmong continued to climb, to 36.0/ 100000 from 1996 through 2000, the rates for API (16.4/ $100000)$ and NHW (6.8/100000) continued to decline. Overall, the annual average age-adjusted incidence rates for the 13-year observation period were 31.9/ 100000 for Hmong, 17.9/100000 for API, and 7.4/ 100000 for NHW.

Likewise, the patterns observed for gastric cancer mortality paralleled those of incidence. From 1988 through 1991, the annual average age-adjusted mortality rates in the Hmong, API, and NHW were 25.9/ $100000,12.5 / 100000$, and 5.5/100000, respectively. From 1992 through 1995, the annual mortality rate in the Hmong climbed to $27.4 / 100000$, while the mortality rates for API and NHW dropped, to 12.1/100000 and $4.7 / 100000$, respectively. This pattern continued from 1996 through 2000, as the death rate for Hmong increased to 34.6/100000, and decreased for both API (10.0/100000) and NWH (3.9/100000). The overall annual average age-adjusted mortality rates for the entire 13-year observation period were 30.5/100 000 for Hmong, 11.1/100 000 for API, and 4.6/100000 for NHW.

Rates comparable to those for all gastric cancer sites were also observed when examining the anatomic subsites of gastric antrum, pylorus, overlapping lesion, 


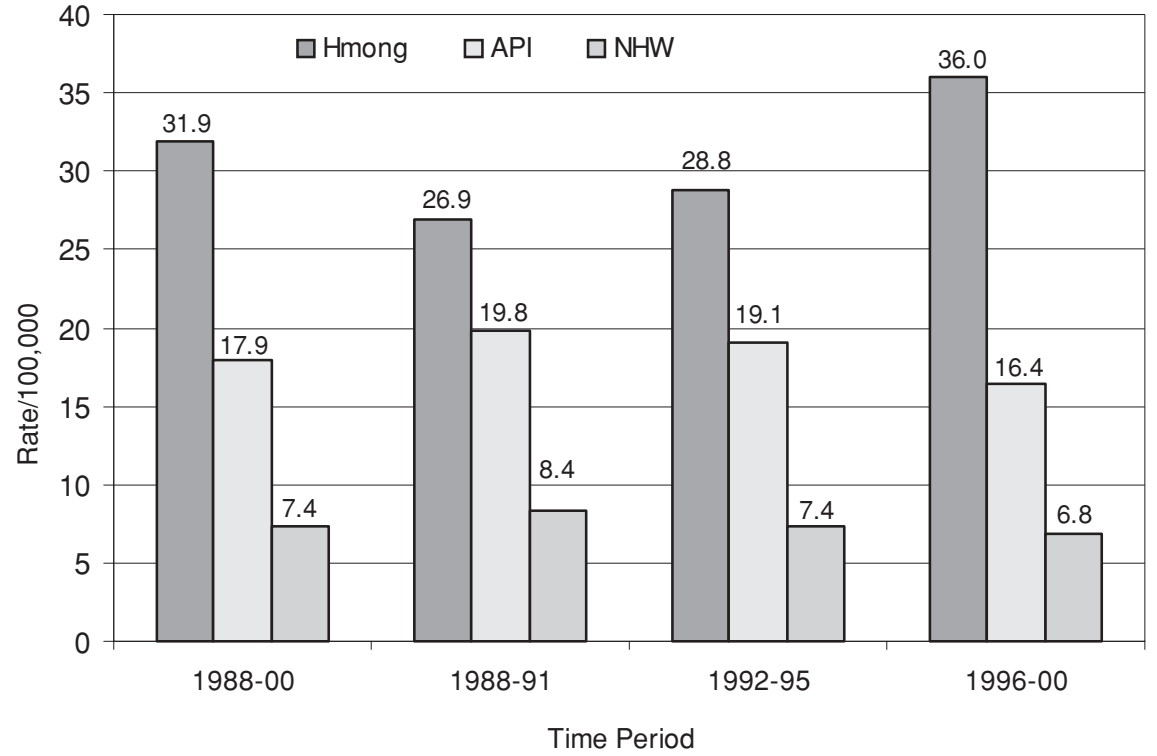

Fig. 1. Annual average age-adjusted incidence rates of stomach cancer, by race/ ethnicity and time periods, in California, 1988-2000. API, Asian Pacific Islanders; NHW, non-Hispanic whites

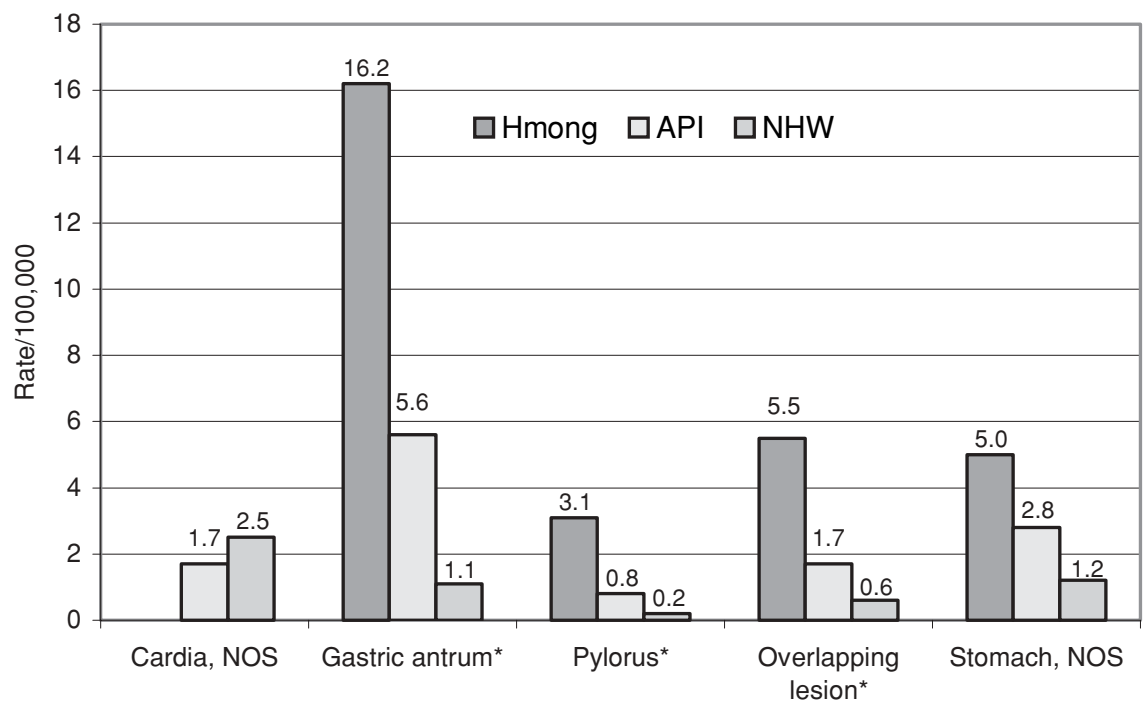

Fig. 2. Annual average age-adjusted incidence rates of stomach cancer, by anatomic subsite and race/ethnicity, in California, 1988-2000. NOS, Not otherwise specified. *Differences were statistically significant $(P$ value, $<0.01)$ and stomach not otherwise specified (NOS; Fig. 2). From 1988 through 2000, the annual average ageadjusted incidence rates for gastric antrum adenocarcinoma for the Hmong, API, and NHW were 16.2/ $100000,5.6 / 100000$, and 1.1/100000, respectively. The incidence rate for gastric pylorus was higher in the Hmong (3.1/100000) than in the API (0.8/100000) and NHW (0.2/100000) combined. Similar incidence rate patterns were also noted for overlapping lesion and stomach NOS for Hmong, API, and NHW. The differences between Hmong, API, and NHW for the subsites gastric antrum, pylorus, and overlapping lesion were statistically significant ( $P$ value, $<0.01$ ).
The average age at diagnosis was roughly equivalent for Hmong, API, and NHW (Table 1). Slightly more Hmong and API than NHW were diagnosed with stomach cancer in the younger age groups, and vice-versa for those 60 years or older. Male-to-female ratios among the three racial, groups were 1.1 for Hmong, 1.3 for API, and 1.8 for NHW.

Grades of gastric carcinoma at diagnosis were comparable among all three ethnic/racial groups. More than half of the three ethnic/racial groups were diagnosed with poorly differentiated gastric carcinoma. Both API and NHW were more likely to be diagnosed with undifferentiated stomach cancer than Hmong. For known 
Table 1. Distribution of patient/tumor characteristics (percentage) by ethnicities for stomach cancer in California, 1988-2000

\begin{tabular}{|c|c|c|c|}
\hline Characteristics & $\begin{array}{l}\text { Hmong } \\
(n=76)\end{array}$ & $\begin{array}{c}\text { API } \\
(n=5052)\end{array}$ & $\begin{array}{c}\text { White } \\
(n=18261)\end{array}$ \\
\hline \multicolumn{4}{|l|}{ Age (years) } \\
\hline Mean (SD) & $67.0(13.7)$ & $66.4(14.7)$ & $70.6(12.9)$ \\
\hline$<20$ & 0.0 & 0.1 & 0.0 \\
\hline $20-39$ & 2.6 & 5.6 & 2.0 \\
\hline $40-59$ & 26.3 & 23.3 & 16.3 \\
\hline $60+$ & 71.1 & 71.0 & 81.7 \\
\hline \multicolumn{4}{|l|}{ Sex } \\
\hline Male & 52.6 & 57.3 & 63.8 \\
\hline Female & 47.4 & 42.7 & 36.2 \\
\hline \multicolumn{4}{|l|}{ Histologic grade at diagnosis } \\
\hline Well differentiated & 2.6 & 3.4 & 4.0 \\
\hline Moderately differentiated & 25.0 & 21.1 & 22.3 \\
\hline Poorly differentiated & 56.6 & 56.8 & 51.6 \\
\hline Undifferentiated & 0.0 & 2.7 & 3.0 \\
\hline Unknown grade & 15.8 & 16.0 & 19.1 \\
\hline \multicolumn{4}{|l|}{ Stage at diagnosis } \\
\hline In situ & 2.7 & 1.4 & 1.1 \\
\hline Localized & 7.9 & 18.5 & 16.5 \\
\hline Regional & 26.3 & 37.9 & 34.7 \\
\hline Distant & 27.6 & 28.1 & 31.5 \\
\hline Unknown & 35.5 & 14.1 & 16.2 \\
\hline \multicolumn{4}{|l|}{ Histologic subtypes } \\
\hline Adenocarcinoma & 83.3 & 88.2 & 84.7 \\
\hline Carcinoma & 10.5 & 4.0 & 4.8 \\
\hline Squamous cell carcinoma & 6.6 & 1.0 & 0.9 \\
\hline Others & 2.6 & 6.8 & 9.6 \\
\hline \multicolumn{4}{|l|}{ First course of treatment } \\
\hline No treatment & 97.4 & 25.6 & 30.3 \\
\hline Surgery & 0.0 & 44.6 & 39.3 \\
\hline $\mathrm{SCR}^{\mathrm{a}}$ & 2.6 & 29.8 & 30.4 \\
\hline \multicolumn{4}{|l|}{ Anatomic subsites } \\
\hline Cardia, NOS & 0.0 & 9.4 & 33.6 \\
\hline Fundus & 0.0 & 3.5 & 5.2 \\
\hline Body & 2.6 & 8.5 & 6.5 \\
\hline Gastric antrum & 52.6 & 31.1 & 15.4 \\
\hline Pylorus & 9.2 & 4.3 & 2.4 \\
\hline Lesser curvature & 4.0 & 13.3 & 8.2 \\
\hline Greater curvature & 0.0 & 5.3 & 4.7 \\
\hline Overlapping lesion & 17.1 & 9.6 & 8.8 \\
\hline Stomach, NOS & 14.5 & 15.0 & 15.2 \\
\hline
\end{tabular}

${ }^{a}$ Combination of surgery, chemotherapy, and radiation

stages at diagnosis, Hmong patients $(10.6 \%)$ were less likely to be diagnosed with the disease at the earlier stages (in situ and local), compared to API (19.9\%) and NHW (17.6\%). Higher percentages of Hmong (35.5\%) cases were unstaged, compared to API $(14.1 \%)$ and NHW $(16.2 \%)$ cases.

Since grade and stage at diagnosis determine treatment options and outcomes, analyses of treatment data indicate that, while all Hmong patients were hospitalized at inpatient care facilities, slightly more than $18 \%, 14 \%$, and $2 \%$ were assigned to a medical oncologist, surgeon, and radiation oncologist, respectively.
First course of treatment, which is another treatment variable, also revealed that more than $97 \%$ of Hmong patients chose no specific treatment, compared to $25.6 \%$ for API and 30.3\% for NHW, even though specialists were assigned to provide the necessary care.

As for histologic subtypes, there was no significant difference among the three ethnic/racial groups. However, analyses by anatomic subsites revealed that Hmong patients $(52.6 \%)$ were more likely to be diagnosed with stomach cancer of the gastric antrum than both API (31.1\%) and NHW (15.4\%) combined. 


\section{Discussion}

This study was based on 76 stomach cancer cases diagnosed in the Hmong population in California from 1988 through 2000. The current results are similar to those previously reported [32,33]. During the 13-year observation period, Hmong suffered gastric cancer incidence rates 1.8 and 4.3 times higher than API and NHW, respectively. These rates increased to 2.2 and 5.3 times when analyses were restricted to 1996 through 2000. Similarly, from 1996 through 2000, Hmong succumbed to 3.5 and 8.9 times more stomach cancer mortality than API and NHW, respectively. For the entire study period, the rates at which Hmong died of gastric cancer were 2.7 and 6.6 times those of API and NHW, respectively.

The observed continuing increase of gastric cancer incidence and mortality rates in the Hmong may be of sociocultural and environmental origins. Daily traditional dietary practices may play a role in the increasing trends. Studies have linked gastric carcinoma to the consumption of high volumes of rice [34] and preserved foods [35]. Mounting epidemiologic evidence has suggested that increased consumption of fruits and vegetables protects against stomach cancer development [36]. The ingestion of fruits and vegetables among the Hmong is minimal, and is infrequent in comparison to that of rice, pork, and chicken [37]. Frequent intake of rice and meat-based meals not only elevates risk of stomach cancer but also coincides with obesity, which predisposes to gastric cancer through chronic acid reflux disease as a result of increasing abdominal weight pressures [38]. In the Hmong culture, being overweight is perceived as being healthy and strong, and body mass index among Hmong adults [39] averages more than $25.5 \mathrm{~kg} / \mathrm{m}^{2}$, which is considered to be moderately overweight.

Low socioeconomic status forced the Hmong to live in dirt-floor, bamboo houses in Laos and Thailand, which facilitated the acquisition of $H$. pylori. Early childhood infection with $H$. pylori has been linked to poor and overcrowded living conditions in China [40] and Thailand [41]. Today, the bacterium is possibly exerting its carcinogenic effects on the Hmong, and it will continue to do so in the foreign-born generations of Hmong living in the United States. With marked improvements in living conditions and socioeconomic status in the United States, rates of stomach cancer should decline as Hmong are acculturated and adopt healthier dietary practices.

When examining stage at diagnosis, social class is less influential than the fact that there is no simple diagnostic tool available to detect gastric carcinoma at the early stages. Data from the current analysis show that Hmong experienced less undifferentiated and late-stage gastric cancer than API and NHW. However, with unstaged disease - which could very well be late-stage gastric carcinoma - being much higher in the Hmong, the lower proportions of undifferentiated and late-stage stomach cancer in the Hmong may be superficial. The higher percentage of poorly differentiated gastric carcinoma observed in API and NHW may simply be attributable to Epstein-Barr virus infection, and may have nothing to do with social class.

With regards to anatomic subsites of the stomach, Hmong suffered 2.9 and 14.7 times more of gastric antrum adenocarcinoma than API and NHW. Infection with $H$. pylori is a possible explanation for the higher incidence rate of gastric antrum adenocarcinoma in the Hmong, as several studies have shown that $H$. pylori is the etiologic agent for gastric antrum adenocarcinoma [42-44]. API and NHW experienced higher incidences of cancer of the gastric cardia, fundus, and other upper portions of the stomach. Currently it is impossible to differentiate true gastric cardia (AEG II) cancer from cancer of the esophagogastric junction (GEJ) in the CCR database. It is possible that the high proportions of gastric cardia in NHW may have included GEJ cases, due to misclassification [45].

Consistent with data from other studies [46,47], results from the current study clearly show that Hmong patients did not seek treatment. More than $97 \%$ of Hmong patients sought neither surgery, radiation, nor chemotherapy for stomach cancer, compared to API (25.6\%) and NHW (30.3\%) even though medical oncologists, surgeons, and radiation oncologists were assigned to provide the care needed. Studies have shown that survival was significantly more favorable for gastric cancer patients who had undergone some sort of surgical resection, compared to those without a treatment $[48,49]$. The "no-treatment" evidence is one of numerous explanations of why more than $92 \%$ of Hmong cancer patients died of the disease. Furthermore, this result is indicative of the underutilization of biomedical care by the Hmong, as they continue to rely on traditional health healings as the first line of defense. The synergistic effect of the lack of diagnostic tools, postponement in seeking healthcare, and not accepting treatment among the Hmong exacerbates the situation even further, which may negatively affect survival or quality of life.

At this juncture, no data are available on H. pylori, Epstein Barr virus, acid reflux disease, and current dietary practices among Hmong living in the United States. Thus, further investigations into the aforementioned variables among Hmong are warranted before any firm conclusion can be drawn, as these variables may impact gastric cancer development. Because traditional religion and health beliefs are pivotal to 
Hmong health healing practices, Hmong should be encouraged to simultaneously seek both traditional and biomedicines for chronic, biologically induced ailments. This will potentially increase their utilization of medical care and the selection of some sort of treatment when serious chronic diseases such as cancers are detected early. Support for concurrent access to traditional and westernized healthcare options is not only culturally responsive but also provides the greatest chance for increasing the acceptance of non-traditional health practices by the Hmong, provided traditional healthcare practices do not interfere with biomedicines.

Acknowledgments This study was funded by a grant from the California Cancer Research Program (No. 3IP0220-P).

\section{References}

1. Quincy K. Hmong, history of a people. 2nd ed. Cheney: Eastern Washington University Press; 1995.

2. Smith L. Critical thinking, health policy, and the Hmong culture, part II. J Cult Divers 1997;4:59-67.

3. U.S. Census Bureau. Summary file 4. Washington, D.C: Public Information Office; 2003.

4. Fadiman A. The spirit catches you and you fall down: a Hmong child, her American doctors, and the collision of two cultures. New York: Farrar, Straus and Giroux; 1998.

5. Johnson SK. Hmong health beliefs and experiences in the western health care system. J Transcult Nurs 2002;13:126-32.

6. Fuchs CS, Mayer RJ. Gastric carcinoma. N Engl J Med 1995; 333:32-41.

7. Graziano F, Humar B, Guilford P. The role of the E-cadherin gene $(\mathrm{CDH1})$ in diffuse gastric cancer susceptibility: from the laboratory to clinical practice. Ann Oncol 2003;14:1705-13.

8. Yonemura Y, Endou Y, Kimura K, Fushida S, et al. Inverse expression of S100A4 and E-cadherin is associated with metastatic potential in gastric cancer. Clin Cancer Res 2000;6:423442.

9. Hao Z, Koriyama C, Akiba S, Li J, et al. The Epstein-Barr virusassociated gastric carcinoma in southern and northern China. Oncol Rep 2002;9:1293-8.

10. zur Hausen A, Brink AA, Craanen ME, Middeldorp JM, et al. Unique transcription pattern of Epstein-Barr virus (EBV) in EBV-carrying gastric adenocarcinomas: expression of the transforming BARF1 gene. Cancer Res 2000;60:2745-8.

11. Palli D, Saieva C, Coppi C, Del Giudice G, et al. O6Alkylguanines, dietary $N$-nitroso compounds, and their precursors in gastric cancer. Nutr Cancer 2001;39:42-9.

12. Tsugane S, Sasazuki S, Kobayashi M, Sasaki S. Salt and salted food intake and subsequent risk of gastric cancer among middle-aged Japanese men and women. Br J Cancer 2004;90: 128-34.

13. Ye WM, Yi YN, Luo RX, Zhou TS, et al. Diet and gastric cancer: a case-control study in Fujian province, China. World J Gastroenterol 1998;4:516-18.

14. Sriamporn S, Setiawan V, Pisani P, Suwanrungruang K, et al. Gastric cancer: the roles of diet, alcohol drinking, smoking and Helicobacter pylori in northeastern Thailand. Asian Pac J Cancer Prev 2002;3:345-52.

15. Parsonnet J, Friedman GD, Vandersteen DP, Chang Y, et al. Helicobacter pylori infection and the risk of gastric carcinoma. $\mathrm{N}$ Engl J Med 1991;325:1127-31.
16. Nomura A Stemmermann GN, Chyou PH, Kato I, et al. Helicobacter pylori infection and gastric carcinoma among Japanese Americans in Hawaii. N Engl J Med 1991;325:1132-6.

17. The Eurogast Study Group. An international association between Helicobacter pylori infection and gastric cancer. Lancet 1993; 341:1359-62.

18. International Agency for Research on Cancer. IARC working group on the evaluation of carcinogenic risks to humans: schistosomes, liver flukes and Helicobacter pylori. IARC Monogr Eval Carcinog Risks Hum 1994;61:177-240.

19. Smith GD, Hart C, Blane D, Hole D. Adverse socioeconomic conditions in childhood and cause-specific adult mortality: prospective observational study. BMJ 1998;316:1631-5.

20. Fall CH, Goggin PM, Hawtin P, Fine D, et al. Growth in infancy, infant feeding, childhood living conditions, and Helicobacter pylori infection at age 70. Arch Dise Child 1997;77:310-14.

21. Patel P, Mendall MA, Khulusi S, Northfield TC, et al. Helicobacter pylori infection in childhood: risk factors and effect on growth. BMJ 1994;309:1119-23.

22. Roder PM. The epidemiology of gastric cancer. Gastric Cancer 2002;5:5-11.

23. Parkin DM, Muir C, Whelan SL, Ga OYT, et al. Cancer incidence of five continents, vol VI. Lyon: IARC Scientific Publication No. 120; 1992.

24. Parkin DM, Pisani P, Ferlay J. Estimates of the worldwide incidence of 25 major cancers in 1990. Int J Cancer 1999;80:827-41.

25. Nomura A. Stomach cancer. In: Schottenfeld DS, Fraumeni JF Jr, (editors.) Cancer epidemiology and prevention. New York: Oxford University Press; 1996: p. 707-24.

26. van den Brandt PA, Botterweck AA, Goldbohm RA. Salt intake, cured meat consumption, refrigerator use and stomach cancer incidence: a prospective cohort study (Netherlands). Cancer Causes Control 2003;14:427-38.

27. Harris A. Current regimens for treatment of Helicobacter pylori infection. Br Med Bull 1998;54:195-205.

28. Stadtländer CTK-H, Waterbor JW. Molecular epidemiology, pathogenesis and prevention of gastric cancer. Carcinogenesis 1999;20:2195-207.

29. Jackson NC, Worneli B, Wickens S. California cancer reporting standards, volume III. Sacramento, CA: Department of Health Services, California Cancer Registry; 2000.

30. Yang RC, Mills PK, Riordan DG. Cervical cancer among Hmong women in California, USA, 1988-2000. Am J Prev Med 2004; 27:132-8.

31. Remington RD, Schork MA. Demography and vital statistics. Statistics with applications to biological and health sciences. Englewood Cliffs, NJ: Prentice-Hall; 1970: p. 330-1.

32. Mills P, Yang R. Cancer incidence in the Hmong of central California, United States, 1987-94. Cancer Causes Control 1997; 8:705-12.

33. Ross JA, Xie Y, Kiffmeyer WR, Bushhouse S, et al. Cancer in the Minnesota Hmong population. Cancer 2002;97:3076-9.

34. Masaki M, Sugimori H, Nakamura K, Tadera M. Dietary patterns and stomach cancer among middle-aged male workers in Tokyo. Asian Pac J Cancer Prev 2003;4:61-6.

35. You WC, Blot WJ, Chang YS, Ershow AG, et al. Diet and high risk of stomach cancer in Shandong, China. Cancer Res 1998;48: 3518-23.

36. Sauvaget C, Nagano J, Hayashi M, Spencer E, et al. Vegetables and fruit intake and cancer mortality in the Hiroshima/Nagasaki life span study. Br J Cancer 2003;88:689-94.

37. Ikeda JP, Ceja DR, Glass RS, Hardwood JO, et al. Food habits of the Hmong living in Central California. J Nurs Educ 1991;23:16875.

38. Devesa SS, Blot WJ, Fraumeni JF Jr. Changing patterns in the incidence of esophageal and gastric carcinoma in the United States. Cancer 1998, 83:2049-53.

39. Yang R. The relationship between demographic variables and diabetes knowledge among the Hmong community. Master's 
thesis. Fresno, CA: California State University, Fresno, Henry Madden Library; 1998.

40. Yuan JM, Yu MC, Xu WW, Cockburn M, et al. Helicobacter pylori infection and risk of gastric cancer in Shanghai, China: updated results based upon a locally developed and validated assay and further follow-up of the cohort. Cancer Epidemiol Biomarkers Prev 1999;8:621-4.

41. Perez-Perez GI, Tayler DN, Bodhidatta L, Wongsrichanalai J, et al. Seroprevalence of Helicobacter pylori infections in Thailand. J Infect Dis 1990;161:1237-41.

42. Forman D, Newell DG, Fullerton F, Yarnell JW, et al. Association between infection with Helicobacter pylori and risk of gastric cancer: evidence from a prospective investigation. BMJ 1991;302: 1302-5.

43. Nomura AM, Lee J, Stemmermann GN, Nomura RY, et al. Helibacter pylori CagA seropositivity and gastric carcinoma risk in a Japanese American population. J Infect Dis 2002;186:113844.
44. Parsonnet J, Hansen S, Rodriguez L, Gelb AB, et al. Helicobacter pylori infection and gastric lymphoma. N Engl J Med 1994;330: 1267-71.

45. Ekstrom AM, Signorello LB, Hansson L, Bergstrom R, et al. Evaluating gastric cancer misclassification: a potential explanation for the rise in cardia cancer incidence. J Natl Cancer Inst 1999;91:786-90.

46. Nuttall P, Florez FC. Hmong healing practices used for common childhood illnesses. Pediatr Nurs 1997;23:247-51.

47. Cheon-Klessing Y, Camilleri D, McElmurry B, Ohlson V. Folk medicine in the health practice of Hmong refugees. West J Nurs Res 1988;20:647-60.

48. Carson W, Karakousis C, Douglass H, Rao U, et al. Results of aggressive treatment of gastric sarcoma. Ann Surg Oncol 1994;1: 244-51.

49. Zhang XF, Huang CM, Lu HS, Wu XY, et al. Surgical treatment and prognosis of gastric cancer in 2613 patients. World J Gastroenterol 2004;10:3405-8. 